\title{
Marquis De Bombelles, Journal
}

\section{Maria Immacolata Spagna}

\section{(2) OpenEdition}

\section{Journals}

\section{Edizione digitale}

URL: https://journals.openedition.org/studifrancesi/39486

DOI: 10.4000/studifrancesi.39486

ISSN: 2421-5856

\section{Editore}

Rosenberg \& Sellier

\section{Edizione cartacea}

Data di pubblicazione: 1 décembre 2004

Paginazione: 380

ISSN: 0039-2944

\section{Notizia bibliografica digitale}

Maria Immacolata Spagna, «Marquis De Bombelles, Journal», Studi Francesi [Online], 143 (XLVIII | II) | 2004, online dal 30 novembre 2015, consultato il 19 mai 2021. URL: http://journals.openedition.org/ studifrancesi/39486 ; DOI: https://doi.org/10.4000/studifrancesi.39486

Questo documento è stato generato automaticamente il 19 mai 2021.

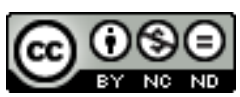

Studi Francesi è distribuita con Licenza Creative Commons Attribuzione - Non commerciale - Non opere derivate 4.0 Internazionale. 


\title{
Marquis De Bombelles, Journal
}

\author{
Maria Immacolata Spagna
}

\section{NOTIZIA}

MARQUIS DE BOMBELLES, Journal, Tome V, texte établi, présenté et annoté par Jeannine CHARON-BORDAS, Jean GRASSION et Frans DURIF. Genève, Librairie Droz, 2002 («Histoire des idées et critique littéraire», vol. 398), pp. 519.

1 Il Journal del marchese de Bombelles, iniziato nel 1780, in occasione della nascita del suo primogenito, si conclude nel 1822 con la morte dell'autore. Comprende novantasette volumi manoscritti conservati in un castello austriaco da uno dei discendenti del marchese, il conte Clam Martinic che ne ha autorizzato la pubblicazione. Il presente tomo riprende la parte del Journal, che copre il periodo che va dal novembre 1795 alla fine del 1800 . Esso si apre subito dopo la dissoluzione della Convenzione alla fine dell'ottobre 1795 con cui si chiude il tomo IV e si conclude con la duplice tragedia personale del marchese: la morte della moglie e del neonato Armand, il settimo dei suoi figli.

2 Questa parte del Journal del marchese de Bombelles permette di conoscere le tribolazioni di una famiglia di emigrati tra il 1795 e il 1800. Dopo aver lasciato il castello di Wardegg in Svizzera, la famiglia de Bombelles si era stabilita nel settembre 1794 a Ratisbona, dove visse per un po' di tempo con una famiglia inglese conosciuta a Venezia, i Winne, che li aveva seguiti prima a Wardegg poi in questo nuovo esilio. Grazie alla pensione che gli era stata accordata dalla regina Maria-Carolina di Napoli in occasione del suo passaggio nel 1791 a Venezia, dove de Bombelles era ancora ambasciatore della Francia, il marchese aveva potuto sfuggire alle difficoltà finanziarie che conobbero molti emigrati. Questo fatto gli consentì tra l'altro di accogliere in casa sua i figli, il loro precettore e la sorella del duca di Villequier, chiamato presso Luigi XVIII allora a Verona, il cavaliere d'Hautpoul, la sorella di Marc-Marie de Bombelles, Mme de Louvois, il cugino Florent-Louis de Bombelles, l'abbé de La Brosse che faceva 
loro da segretario e l'abbé Aurel (o Aurèle), anche lui in qualità di segretario, oltre che di precettore dei bambini del marchese.

3 Nel 1796, mentre l'Austria restava in guerra con la Francia, il marchese, preoccupato dall'avanzata delle truppe francesi, pensò di mettere al sicuro la sua famiglia e ottenne, non senza difficoltà, una residenza a Brünn in Moravia, dove il marchese conoscerà la noia e l'ostilità delle autorità austriache. Questa piccola città, situata presso la capitale austriaca, era luogo di passaggio per molti emigrati francesi, nobili austriaci o tedeschi, diplomatici e ufficiali che de Bombelles riceveva o a cui rendeva visita; si fece, dunque, degli amici, in particolare il conte e la contessa di Zierotin, che gli saranno di grande aiuto nei momenti difficili. Il marchese, inoltre, si recava spesso a Vienna dove incontrava i membri della nobiltà imperiale a cui era legato, emigrati come il vescovo di Nancy, La Fare, ambasciatore ufficiale della Maison de Bourbon, vecchi amici, come il principe de Ligne rifugiato nella capitale e con il quale il marchese corrispondeva abbastanza regolarmente.

4 Nel 1800, in seguito all'incertezza di pagamento della pensione di Maria-Carolina di Napoli, de Bombelles ottenne una risposta favorevole dal principe di Condé e raggiunse la sua armata, ormai esausta e senza speranza, stazionata in Baviera. Il marchese ritrovò qui amici, suo cugino il barone de Bombelles e divenne un confidente del principe di Condé e dei duchi d'Angoulême, di Berry e d'Enghien. Questi anni segnano la fine della Rivoluzione ed il ritorno in Francia di numerosi emigrati, rientro che amareggiava de Bombelles perché per lui la Francia senza il suo re non era più il suo paese. Il marchese era ostile al giuramento di fedeltà alla costituzione voluto dagli ecclesiastici che rientravano in Francia ben accolti dalla popolazione ed incoraggiati da Bonaparte. La prova più crudele per il marchese, tuttavia, sarà la morte della sua donna e del suo piccolo Armand nel settembre 1800; a questo dramma personale si aggiungono l'agonia dell'esercito di Condé, le preoccupazioni finanziarie e l'avvenire compromesso dei suoi figli.

5 Il testo non è integrale, come spiega J. Charon-Bordas, uno dei curatori di questa edizione critica, nella sua introduzione: a causa della prolissità dei materiali contenuti nei cahiers sono stati esclusi gli articoli, i decreti o altri documenti di leggi, trattati, citazioni, commenti di letture, ecc. già editi. Ciò nonostante il volume ripropone, in appendice, tre brevissimi testi precedentemente pubblicati: il racconto della giornata che ha preceduto la morte di Luigi XVI fatto da Cléry, domestico del re, davanti alla famiglia de Bombelles in esilio a Ratisbona; il testamento del marchese de Bombelles e le ultime volontà della moglie.

6 Questo tomo del Journal conferma la curiosità dei lettori e l'interesse degli storici a tuffarsi nel racconto della cronaca quotidiana del marchese de Bombelles all'indomani della Rivoluzione francese. Il Journal del marchese, un uomo che ha vissuto accanto a principi, sovrani, ufficiali militari e vescovi, costituisce in effetti un documento prezioso sul XVIII secolo, ed in particolare sul periodo che ha visto la fine dell'Ancien Régime, che offre il punto di vista di un aristocratico e di un nobile intransigente che rifiuta ogni compromesso che si ponga in contraddizione con il suo forte desiderio di ristabilire la monarchia. 